\title{
CONSTRUÇÕES VERNÁCULAS EM TERRA: PERSPECTIVA HISTÓRICA, TÉCNICA E CONTEMPORÂNEA DA TAIPA DE MÃO
}

\section{VERNACULAR CONSTRUCTIONS IN EARTH: HISTORICAL, TECHNICAL AND CONTEMPORARY PERSPECTIVE OF HAND TAIPA}

\author{
Carol Cardoso Moura Cordeiro ${ }^{1}$ \\ Programa de Pós-graduação em Engenharia de Edificações e Ambiental, Cuiabá, MT, Brasil, carolcardoso.eng@gmail.com \\ Douglas Queiroz Brandão ${ }^{2}$ \\ Programa de Pós-graduação em Engenharia de Edificações e Ambiental, Cuiabá, MT, Brasil, dbrandao@ufmt.br \\ Luciane Cleonice Durante ${ }^{3}$ \\ Programa de Pós-graduação em Engenharia de Edificações e Ambiental, Cuiabá, MT, Brasil, luciane.durante@hotmail.com \\ Ivan Júlio Apolônio Callejas ${ }^{4}$ \\ Programa de Pós-graduação em Engenharia de Edificações e Ambiental, Cuiabá, MT, Brasil, ivancallejas1973@gmail.com
}

\begin{abstract}
Resumo
Amplamente utilizadas nas civilizações do passado, as construções vernáculas com terra foram substituídas por técnicas e materiais industrializados em decorrência dos avanços tecnológicos do setor da construção civil para suprir as exigências dos usuários modernos. Em vista dos impactos ambientais oriundos dessa substituição, têm-se buscado alternativas construtivas inspiradas nessas antigas construções, uma vez que o material está disponível no próprio local e não se incorpora processos de queima na sua produção. Assim sendo, o objetivo dete artigo é evidenciar as potencialidades das construções em taipa de mão, sob a perspectiva da história, da técnica e da contemporaneidade. Utilizou-se a metodologia de revisão sistemática da literatura, considerando publicações de língua portuguesa e inglesa, em uma janela temporal de 20 anos. Os resultados apresentam uma classificação dos sistemas construtivos com terra no panorama mundial e um destaque para o registro histórico e mapeamento da taipa de mão no Nordeste, Centro-Oeste e Sudeste brasileiro, assim como suas potencialidades no cenário atual. Como contribuição, discutem-se vantagens e desvantagens da taipa de mão, apontando aspectos técnicos que precisam ser incorporados para que se torne uma alternativa viável para construções sustentáveis.
\end{abstract}

Palavras-chave: Pau-a-pique. Construções Sustentáveis. Arquitetura Vernácula.

\begin{abstract}
Widely used in civilizations of the past, vernacular land constructions have been replaced by industrialized techniques and materials as a result of the technological advances of the construction industry to meet the requirements of modern users. Given the environmental impacts resulting from this substitution, we have sought constructive alternatives inspired by these old constructions, since the material is available locally and does not incorporate burning processes in its production. Therefore, the purpose of this paper is to highlight the potential of hand-made mud constructions from the perspective of history, technique, and contemporaneity. The methodology of systematic literature review was used, considering publications of Portuguese and English language, in a temporal window of 20 years. The results present a classification of the construction systems with earth in the world panorama and a highlight of the historical record and mapping of the hand-made mud constructions in the Northeast, Center-West, and Southeast of Brazil, as well as its potentialities in the current scenario. As a contribution, the advantages and disadvantages of this construction type are discussed, pointing out technical aspects that need to be incorporated to become a viable alternative for sustainable constructions.
\end{abstract}

Keywords: Pau-a-pique. Sustainable Constructions. Vernacular Architecture.

How to cite this article:

CORDEIRO, Carol Cardoso Moura et al. Construções vernáculas em terra: perspectiva histórica, técnica e contemporânea da taipa de mão. PARC Pesquisa em Arquitetura e Construção, Campinas, SP, v. 10, p. e019006, jan. 2019. ISSN 19806809. Disponível em: <https://periodicos.sbu.unicamp.br/ojs/index.php/parc/article/view/8651212>. Acesso em: 02 jan. 2019. doi:https://doi.org/10.20396/parc.v10i0.8651212. 


\section{Introdução}

Desde a pré-história, o homem usufruía de recursos naturais e técnicas rudimentares para construir abrigos que oferecessem proteção e segurança para sua família. Foi na natureza que, há cerca de dez mil anos, foram encontrados os elementos necessários pedra, madeira e barro - para construir as primeiras habitações (OLENDER, 2006). Utilizando recursos locais e métodos apropriados ao modo de habitar específico de cada comunidade, essas construções empíricas, denominadas como vernáculas, estabeleceram estratégias para inserir as edificações ao meio em que pertenciam (FERNANDES; MATEUS; BRAGANÇA, 2012; FIGUEIRA, 2015). Em virtude dessas estratégias, surgiram diversas técnicas construtivas para adaptar as edificações às condições climáticas, aos materiais autóctones e às características culturais de cada região do mundo.

Entretanto, ao longo dos anos, o anseio da nova sociedade por edificações mais modernizadas, para assim suprir suas necessidades não mais correspondidas pelas técnicas construtivas rudimentares, subsidiou o desenvolvimento de materiais industrializados na construção civil. A transformação de matéria-prima em produtos manufaturados para esse setor representou, no imaginário cosmopolita, uma evolução da forma de morar.

Nesse contexto, as construções com terra, que eram utilizadas por quase todas as civilizações do passado, sendo, inclusive, protagonistas em diversas obras espalhadas pelo mundo, passou um período em desuso (CUNHA et al., 2015).

Figueira (2015) coloca o período da Revolução Industrial como divisor entre construções com técnicas pré-industriais e a posterior substituição por mecanismos de produção automatizados no pós-industrial.

Já Sameh (2014) atribui esse desuso a três situações. A primeira, também associada à tecnologia, resulta do domínio do monopólio industrial, que passou a controlar o mercado de materiais de construção convencionais, como aço e concreto, e incentivou o declínio de técnicas tradicionais, criando uma barreira e um revés na defesa da terra e de outros materiais de construção naturais. A segunda, devido às alegações negativas quanto a segurança e durabilidade da terra, que afetam a sua aceitação na sociedade muitos consideram a arquitetura em terra como primitiva, ligada a baixa classe social e culturalmente associada à pobreza. A terceira, por sua vez, considera o fator da alta densidade no ambiente construído urbano, que pode dificultar a aquisição de terra no entorno devido à disponibilidade, o que acarreta aumento de preço.

Todavia, considerando-se uma abordagem ambiental, essa substituição resultou em grandes perdas, uma vez que a indústria da construção civil é um dos setores produtivos que mais utiliza recursos naturais, desde a produção de insumos, transporte, execução das obras, até o uso e operação das edificações (SOUZA et al., 2015).

Esses impactos gerados pela construção civil são associados por Cunha et al. (2015) ao alto consumo de energia, água e gás carbônico $\left(\mathrm{CO}_{2}\right)$ na produção de insumos e na própria execução de obras de engenharia.

Baseado em estudos internacionais, Carvalho e Lopes (2012) apresentam que a construção e o uso dos edifícios implicam no consumo de $50 \%$ dos recursos naturais, $40 \%$ da energia e $16 \%$ da água, representando $25 \%$ das emissões totais dos gases que promovem o efeito estufa, especialmente o CO2. No Brasil, Souza et al. (2015) afirmam que $75 \%$ do que é extraído para esse fim advém do meio natural, indicando que o setor consome demasiada quantidade de materiais com alto teor energético, como aço, cerâmica, alumínio e cimento. 
Tendo em vista esse revés gerado ao meio ambiente, refletido em mudanças climáticas, eminência de crise energética, concentração populacional e consumo exacerbado de recursos naturais, têm-se discutido medidas de sustentabilidade sem o dispêndio de grandes somas energéticas, com uso racional de matérias-primas renováveis, não poluentes, duráveis e passíveis de reaproveitamento (CARVALHO; LOPLES, 2012). Segundo Sameh (2014) esse insucesso ambiental tem levado muitos países a concentrar seus esforços em buscar a redução da pegada de carbono no setor da construção, investigando materiais de menor impacto sobre o meio ambiente, como a terra.

Pacheco-Torgal e Jalali (2011) fazem um comparativo entre o uso da alvenaria convencional e a terra, onde, naquela, os insumos estão quase sempre distantes dos locais de construção, implicando na obrigatoriedade do uso de transporte, os quais são responsáveis pelas emissões de gases de efeito estufa. Ainda em comparação as obras tradicionais, tem-se que os resíduos de construção com terra podem ser depositados no local de sua extração sem qualquer risco ambiental envolvido, podendo ainda serem reutilizados, contrariamente aos industrializados.

Nessa perspectiva, o resgate das técnicas de construção com terra se torna uma alternativa oportuna para edificar moradias sustentáveis, contribuindo para a mitigação de problemas ambientais, sendo atualmente abordado por diversos autores na literatura atual. Pacheco-Torgal e Jalali (2011) retratam que, a construção com terra recebeu, na última década, uma atenção crescente por parte da comunidade científica, ilustrada por um aumento de dez vezes nas publicações, quando comparadas com a década anterior. Exemplos disso são os trabalhos internacionais recentes desenvolvidos por Joffroy, Guillaurd e Le Tiec (2013), Cunha et al. (2015), Pinto et al. (2011), Sameh (2014) e Franke (2017) que tratam da terra em aplicações diversas.

Esse retorno pode ser exemplificado por diversas obras: i) Na França, a partir de 1980, com as habitações do Domaine de la Terre e o programa de habitação social com o uso de terra compactada, com a construção de milhares de habitações na llha de Mayote; ii) na Inglaterra, em 1990, a iniciativa de produzir e comercializar materiais de construção relacionados à terra como tijolos, painéis e a própria terra entregue em sacos, permitiu a expansão na região europeia; iii) na Alemanha, onde estudos da Universidade de Kassel, nas décadas de 1970 e 1980, desenvolveram projetos para criar uma arquitetura flexível 35 de terra, que, posteriormente, foi experimentada em vários projetos habitacionais e de instalações públicas. A partir de então, eventos se multiplicaram no país para conscientizar e promover uma arquitetura ecológica que atenda às expectativas da sua sociedade; iv) na Áustria, entre os anos de 2012 e 2013, iniciou-se um processo de pré-fabricação de paredes de terra totalmente mecanizadas; v) em Portugal, por meio das universidades que possuem cursos especializados para formação de arquitetos com domínio do uso da terra e escolas que oferecem cursos para futuros pedreiros e empresários (JOFFROY; GUILLAURD; LE TIEC, 2013).

Analogamente, a rede internacional de âmbito ibero-americano PROTERRA, fundada em 2001, também tem atuado no desenvolvimento da arquitetura e construção com terra, proporcionando a difusão de técnicas para a comunidade, tanto para futuros usuários como para profissionais interessados (NEVES, 2004).

Recentemente, Cunha et al. (2015) e Pinto et al. (2011), em Portugal, desenvolveram estudos sobre construção com terra, muito utilizada no país, buscando avaliar o seu comportamento térmico associado a outros materiais. Visavam atender aos requisitos de conforto térmico atuais, inspirando soluções de construção inovadoras na prática industrial moderna, bem como apoiar tecnicamente futuras ações na manutenção e renovação de antigas construções. Já Sameh (2014), no Egito, tratou do uso de terra 
como um material tradicional oportuno para a sustentabilidade no setor de construção e para suprir as demandas com preços mais acessíveis no país.

No Brasil, muitos autores têm discorrido sobre o seu uso no país, principalmente tratando da taipa de mão, uma das técnicas mais antigas e presentes no território brasileiro, evidenciando sua importância na conjuntura da arquitetura de terra nacional (CASER; INO, 2001; OLENDER, 2006; CANTEIRO; PISANI, 2006; GALDINO, 2010; LOPES et al., 2013; CARVALHO; MIRANDA, 2015).

Nesse contexto, este artigo tem como objetivo geral evidenciar as potencialidades das construções em taipa de mão, sob a perspectiva da história, da técnica e da contemporaneidade. Os objetivos específicos são: a) Reconhecer as principais técnicas de construção vernácula que possuem a terra como matéria-prima; b) Apresentar um panorama mundial atual de sua utilização; c) Elaborar um registro histórico da técnica taipa de mão no Brasil e d) Identificar suas origens e distribuição espacial no país.

A partir do uso do conhecimento científico acerca das experiências de tradição secular das construções edificadas no passado, pode-se pensar em modernização dos procedimentos construtivos com incorporação de novas tecnologias (LOPES; INO, 2000). Desta forma, o conhecimento já comprovado pelo uso e senso comum acerca das construções com terra pode conduzir à reflexões e compreensão sobre seu melhor aproveitamento, obtendo partido de suas vantagens em um contexto contemporâneo.

\section{Método}

As revisões sistemáticas de literatura são estudos secundários para mapear, encontrar, avaliar criticamente, consolidar e agregar os resultados de estudos primários. Considera-se sistemática porque deve seguir um modelo explícito, planejado, responsável e justificado, consolidando e agregando os resultados de estudos para gerar um novo conhecimento (MORANDI; CAMARGO, 2015).

O tema de interesse da presente revisão trata das construções vernáculas com terra, especialmente da técnica da taipa de mão, discorrendo historicamente sobre a sua utilização e procedimentos construtivos desde a antiguidade até os dias atuais.

Pretende-se com isso responder as seguintes questões: Como as técnicas de construção com terra se desenvolveram desde a antiguidade até os dias atuais? Como a técnica taipa de mão se inseriu no contexto de construções vernáculas no Brasil e quais as potencialidades da sua utilização na contemporaneidade?

As bases de buscas utilizadas foram: Portal de Periódicos da CAPES (Coordenação de Aperfeiçoamento de Pessoal de Nível Superior), SciELO (Scientific Electronic Library Online), Science Direct, Google Acadêmico e as bibliotecas digitais da Fundação de Amparo à Pesquisa (FAPESP), do Centro de Referência e Informação em Habitação (INFOHAB), Universidade Federal de Santa Catarina (UFSC), Universidade Federal da Bahia (UFBA) e Universidade de São Paulo (USP).

Considerando um recorte temporal de 20 anos, as buscas em português envolveram os descritores "taipa", "pau a pique", "taipa de sebe" e "taipa de mão". A primeira busca com o descritor "taipa" gerou resultados com temas muito amplos. Com os descritores "pau a pique", "taipa de seba" e "taipa de mão", os resultados gerados se relacionavam a outras disciplinas. Então, definiu-se a busca com a combinação de dois descritores: "pau a pique" and "constru*", "pau a pique" and "habitaç*”, "taipa de mão" and "constru*", "taipa de mão" and "habitaç*”, "taipa de sebe" and "constru*", "taipa de sebe" and "habitaç*", que resultou em informações relevantes para a pesquisa. Também foram realizadas buscas em inglês com os descritores "quincha" e "tabique". 
As publicações resultantes das buscas foram pré-selecionadas por meio da leitura de seus títulos e resumos. Em seguida, procedeu-se à leitura integral das publicações, que foram analisadas seguindo os pressupostos de Dresch, Lacerda e Antunes Júnior (2014), adotando uma metodologia para pré-avaliar a qualidade destes, conforme demonstrado no Quadro 1. Nessa análise, consideraram-se três dimensões: qualidade da execução, adequação à questão da revisão e adequação ao foco da revisão.

Quadro 1-Critérios para avaliação das dimensões da qualidade dos estudos utilizados na revisão sistemática.

\begin{tabular}{|c|c|c|c|}
\hline $\begin{array}{l}\text { Dimensão/ } \\
\text { Qualidade }\end{array}$ & Qualidade da execução do estudo & Adequação à questão da revisão & Adequação ao foco da revisão \\
\hline Alta & $\begin{array}{l}\text { O trabalho atende aos padrões } \\
\text { demandados para o tema em } \\
\text { estudo. }\end{array}$ & $\begin{array}{l}\text { O trabalho abrange o objeto de } \\
\text { estudo da revisão sistemática. }\end{array}$ & $\begin{array}{l}\text { O trabalho apresenta conteúdos } \\
\text { imprescindíveis aos definidas } \\
\text { para a revisão. }\end{array}$ \\
\hline Média & $\begin{array}{l}\text { O trabalho apresenta lacunas em } \\
\text { relação aos padrões demandados } \\
\text { para o tema em estudo. }\end{array}$ & $\begin{array}{c}\text { O trabalho abrange parcialmente } \\
\text { o objeto de estudo da revisão } \\
\text { sistemática. }\end{array}$ & $\begin{array}{c}\text { O trabalho apresenta conteúdos } \\
\text { similares aos definidas para a } \\
\text { revisão. }\end{array}$ \\
\hline Baixa & $\begin{array}{c}\text { O trabalho apresenta } \\
\text { inconformidades em relação aos } \\
\text { padrões demandados para o } \\
\text { tema em estudo. }\end{array}$ & $\begin{array}{l}\text { O trabalho aborda } \\
\text { superficialmente o objeto de } \\
\text { estudo da revisão sistemática. }\end{array}$ & $\begin{array}{c}\text { O trabalho apresenta conteúdos } \\
\text { distintos aos definidas para a } \\
\text { revisão. }\end{array}$ \\
\hline
\end{tabular}

Fonte: Adaptado de Dresch, Lacerda e Antunes Júnior (2014)

Após a análise individual dos trabalhos pré-selecionados para compor a revisão sistemática, as avaliações foram consolidadas de modo a fornecer um conceito final que qualificasse a aderência dos respectivos trabalhos à revisão em questão (DRESCH; LACERDA; ANTUNES JÚNIOR, 2014). Desta forma, adotou-se como critério de inclusão na revisão sistemática os trabalhos que apresentassem avaliação alta no critério de da qualidade ponderada, conforme designado no Quadro 2.

Quadro 2- Critério ponderação da qualidade das fontes para inclusão no estudo
\begin{tabular}{|c|c|c|c|}
\hline Qualidade da Execução & $\begin{array}{c}\text { Adequação à questão da } \\
\text { revisão }\end{array}$ & $\begin{array}{c}\text { Adequação ao foco da revisão } \\
\text { Critério de Qualidade } \\
\text { Ponderada }\end{array}$ \\
\hline Alta & Alta & Alta & Alta \\
\hline Alta & Alta & Média & Alta \\
\hline Média & Alta & Alta & Alta \\
\hline Alta & Média & Mlta & Média \\
\hline Alta & Média & Média & Média \\
\hline Média & Média & Média & Baixa \\
\hline Média & Baixa & Baixa & Baixa \\
\hline Média & Baixa & Baixa & Baixa \\
\hline Média & Média & Baixa & Baixa \\
\hline Baixa & Baixa & Média & Baixa \\
\hline Baixa & Média & Baixa & \\
\hline Baixa & Média & & \\
\hline
\end{tabular}

Fonte: Adaptado de Dresch, Lacerda e Antunes Júnior (2014)

A avaliação da qualidade é um requisito de inclusão dos trabalhos e, no caso desse artigo, fundamenta-se na obrigatoriedade de obtenção de alta qualidade, considerados os critérios de ponderação da pós-avaliação do Quadro 2.

\section{Resultados}

Foram pré-selecionados 32 trabalhos (Quadro 3) na língua portuguesa e inglesa, sendo Carbajal, Ruiz e Schexnayder (2006), Pacheco-Torgal e Jalali (2011), PINTO et al. (2011), Sameh (2014) e Cunha et al. (2015) os únicos na língua inglesa. Após a aplicação dos critérios de ponderação da qualidade, 13 fontes foram classificadas como de alta relevância, destacados em negrito no Quadro 3. 
CORDEIRO, Carol Cardoso Moura et al.

Construções vernáculas em terra: perspectiva histórica, técnica e contemporânea da taipa de mão

Quadro 3 - Fontes identificadas e ponderação da qualidade indicando alinhamento com o estudo em questão

\begin{tabular}{|c|c|c|c|}
\hline Referência & Ano & Tipo & Alinhamento com o estudo \\
\hline (LOPES; INO, 2000) & 2000 & Artigo & Alta \\
\hline (CASER; INO, 2001) & 2001 & Artigo & Alta \\
\hline (PISANI, 2004) & 2004 & Artigo & Alta \\
\hline (OLENDER, 2006) & 2006 & Dissertação & Alta \\
\hline (GALDINO, 2010) & 2010 & Artigo & Alta \\
\hline (NEVES; FARIA, 2011) & 2011 & Coletânea & Alta \\
\hline (CARVALHO; LOPES, 2012) & 2012 & Artigo & Alta \\
\hline (GONÇALVES; GOMES, 2012) & 2012 & Artigo & Alta \\
\hline (NITO; AMORIM, 2012) & 2012 & Artigo & Alta \\
\hline (LOPES et al., 2013) & 2013 & Artigo & Alta \\
\hline (SANTOS, 2015) & 2015 & Dissertação & Alta \\
\hline (PINHEIRO et al., 2016) & 2016 & Artigo & Alta \\
\hline (FRANKE, 2017) & 2017 & Dissertação & Alta \\
\hline (NEVES, 2004) & 2004 & Artigo & Média \\
\hline (CANTEIRO; PISANI, 2006) & 2006 & Artigo & Média \\
\hline (RODRIGUES; HENRIQUES, 2006) & 2006 & Artigo & Média \\
\hline (PACHECO-TORGAL; TALALI, 2011) & 2011 & Artigo & Média \\
\hline (SAMEH, 2014) & 2014 & Artigo & Média \\
\hline (CARVALHO; MIRANDA, 2015) & 2015 & Artigo & Média \\
\hline (CUNHA et al., 2015) & 2015 & Artigo & Média \\
\hline (CASTELNOU, et al., 2003) & 2003 & Artigo & Baixa \\
\hline (CARBAJAL; RUIZ; SCHEXNAYDER, 2006) & 2006 & Artigo & Baixa \\
\hline (CARIGNANI; AZEREDO; FERREIRA, 2007) & 2007 & Artigo & Baixa \\
\hline (JALALI; EIRES, 2008) & 2008 & Artigo & Baixa \\
\hline (MAIA, 2011) & 2011 & Dissertação & Baixa \\
\hline (RODRIGUES; FAIBER, 2013) & 2013 & Artigo & Baixa \\
\hline (FRANCO et al., 2013) & 2013 & Artigo & Baixa \\
\hline (NEVES, 2014) & 2014 & Dissertação & Baixa \\
\hline (CARIGNANI; REIS, 2014) & 2014 & Artigo & Baixa \\
\hline (FERREIRA, 2014) & 2014 & Tese & Baixa \\
\hline (SOUZA et al., 2015) & 2015 & Artigo & Baixa \\
\hline (MORORO; PEQUENO; CARDOSO, 2015) & 2015 & Artigo & Baixa \\
\hline
\end{tabular}

Fonte: Os autores.

Encaminham-se, a seguir, as análises históricas e técnicas relativas ao uso de terra na construção civil, com foco na utilização da taipa de mão no Brasil e nas vantagens do seu uso na contemporaneidade realizada sobre os 13 trabalhos classificados como de alta relevância para este estudo.

Construções vernáculas com terra

A construção vernácula com terra é uma prática milenar, presente na cultura construtiva tradicional das mais diversas sociedades. Vários autores mencionam a estimativa de que, atualmente, cerca de um terço da população mundial habite casas construídas com terra (GONÇALVES; GOMES, 2012; LOPES et al., 2013; CARVALHO; LOPLES, 2012).

Além das habitações, Gonçalves e Gomes (2012); Nito e Amorim (2012) e Santos (2015) referenciam as construções com terra em monumentos e conjuntos arquitetônicos valiosos do mundo, compondo em 10\% a "Lista do patrimônio cultural da humanidade" da Organização das Nações Unidas para a Educação, a Ciência e a Cultura (UNESCO), exemplificadas pela aldeia de Ait-Bem-Haddou, em Marrocos (Figura 1.a); a cidadela de Chan Chan, no Peru (Figura 1.b); a mesquita de Djenné, no Mali (Figura 1.c); e, a cidade antiga de Shibam, no lémen (Figura 1.d). 


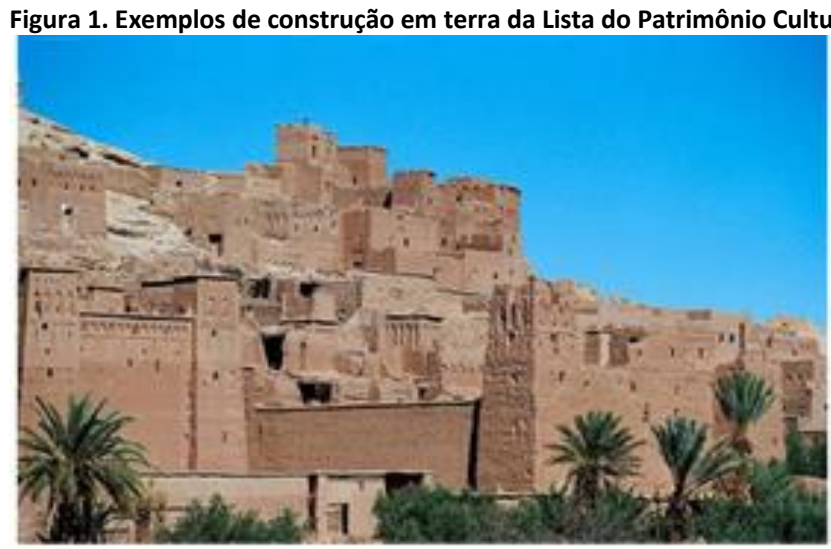

a)

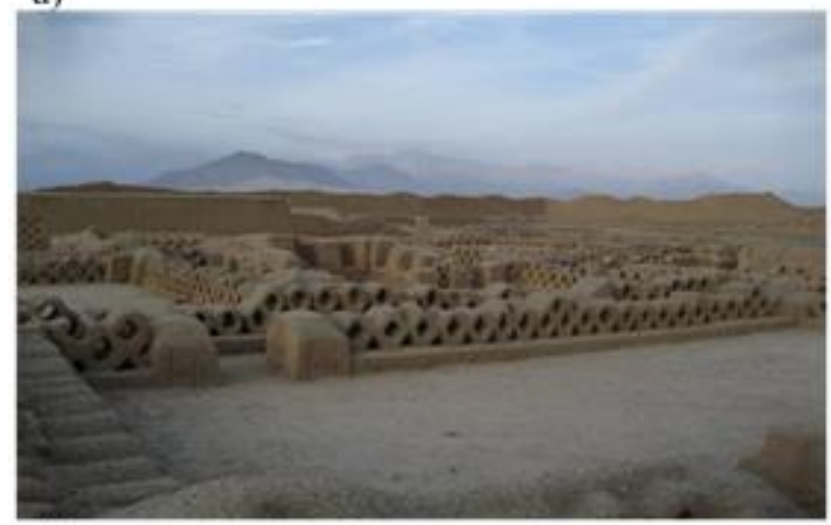

b)

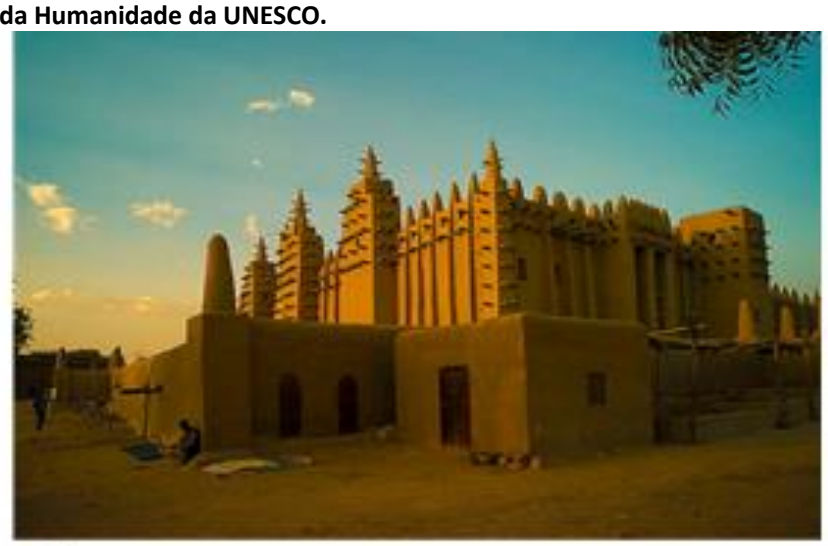

c)

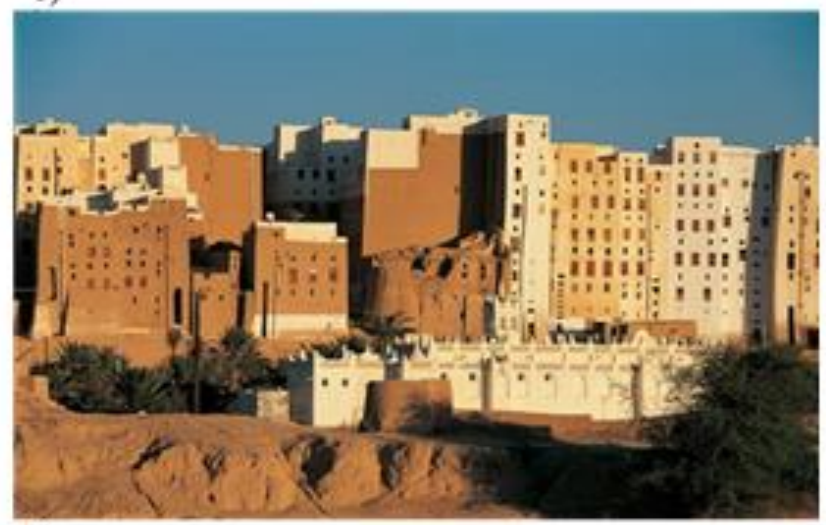

d)

Fonte: UNESCO (2018).

Olender (2006) e Carvalho e Lopes (2012) também citam obras com terra presentes na Palestina, China, Mesopotâmia, Irã, Iraque, Turquia, China, Peru, México e em vários países da África, onde cidades foram construídas com esse material e cuja existência remete a cerca de 8000 anos a.C.

Difundindo-se pelo mundo de maneiras diversas, a terra criou um vasto acervo histórico cultural. De acordo com Olender (2006, p.18),

\begin{abstract}
"As técnicas de utilização da terra foram levadas por esses povos às regiões por eles conquistadas, por esses povos conquistados a outras regiões e, assim, sucessivamente, por todo o mundo através dos séculos, o que explica a sua presença em praticamente todo o planeta".
\end{abstract}

$\mathrm{Na}$ Península Ibérica, foram introduzidas pelos romanos e enriquecidas pelos árabes. $\mathrm{Na}$ América Pré-colombiana as técnicas eram distintas das europeias, já que as civilizações incas e astecas faziam uso desse material antes da chegada dos colonizadores.

Na América Latina, foram trazidas pelos portugueses e espanhóis no período da colonização com inúmeras combinações, adequando-se às formas de construir de acordo com a matéria-prima e o território local (NITO; AMORIM, 2012; CARVALHO; LOPLES, 2012). Diante disso, construções vernáculas com terra estão distribuídas em todos os continentes, conforma retrata a Figura 2, utilizando-se de sistemas construtivos variados de acordo com a região e cultura local. 
CORDEIRO, Carol Cardoso Moura et al.

Construções vernáculas em terra: perspectiva histórica, técnica e contemporânea da taipa de mão

Figura 2. Distribuição da arquitetura de terra no mundo e construções com terra inscritas na lista do patrimônio mundial da UNESCO

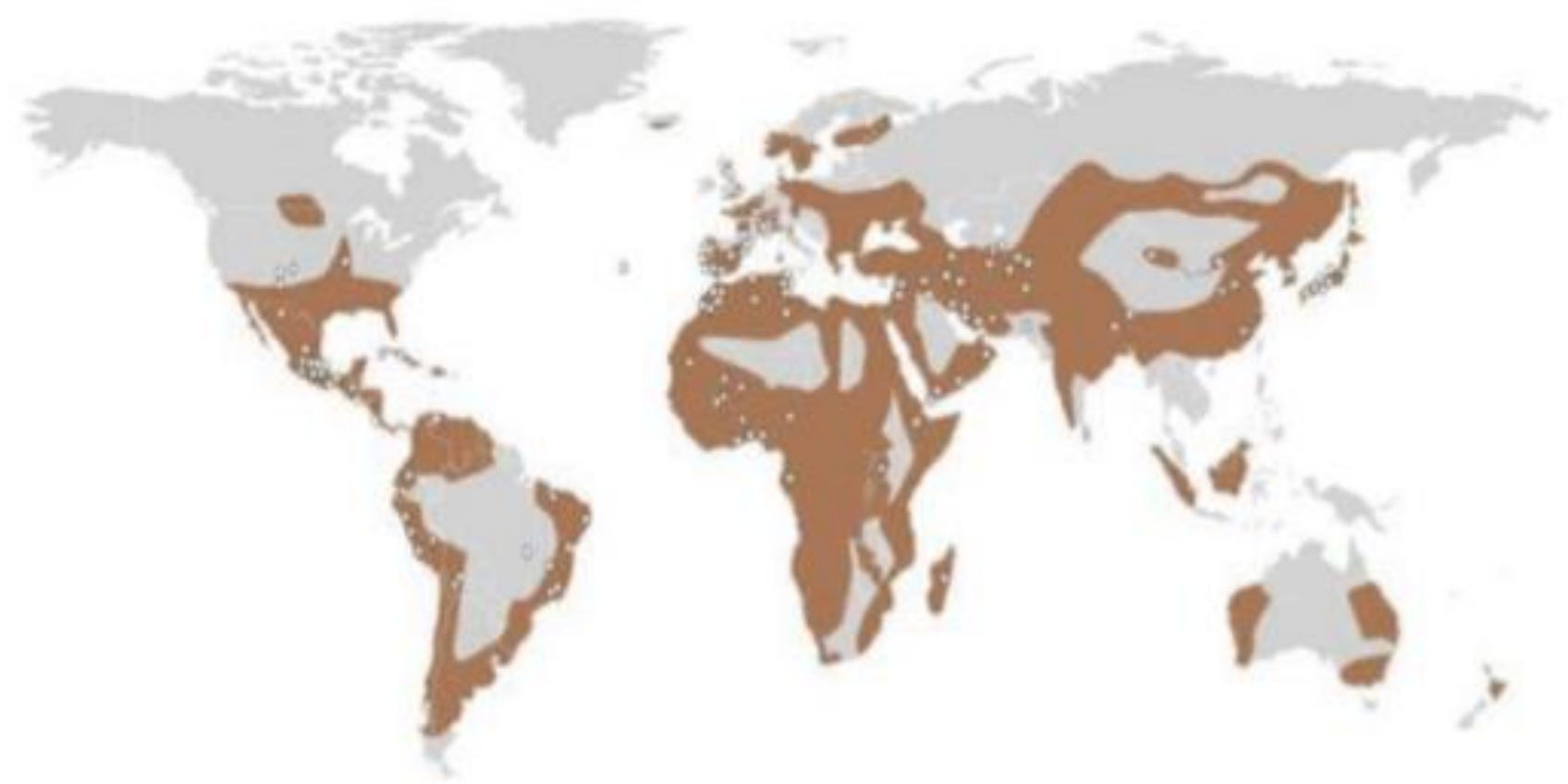

Nota: Zona de construção com terra, O Sítio do patrimônio mundial. Fonte: Santos (2015 apud CRATerre, 2012)

Sobre os tipos de sistemas construtivos com terra, Nito e Amorim (2012) tratam da subdivisão, características e exemplos dos três grupos principais ("A"; "B" e "C", Figura 3), antigos e modernos, que usam essa matéria prima de acordo com o estabelecido pelo Centro Internacional de Construções com Terra (CRATerre) e descritas por Gonçalves e Gomes (2012) a seguir.

Figura 3. Diagrama dos diferentes grupos de sistemas construtivos antigos e modernos que utilizam a terra como matéria-prima.

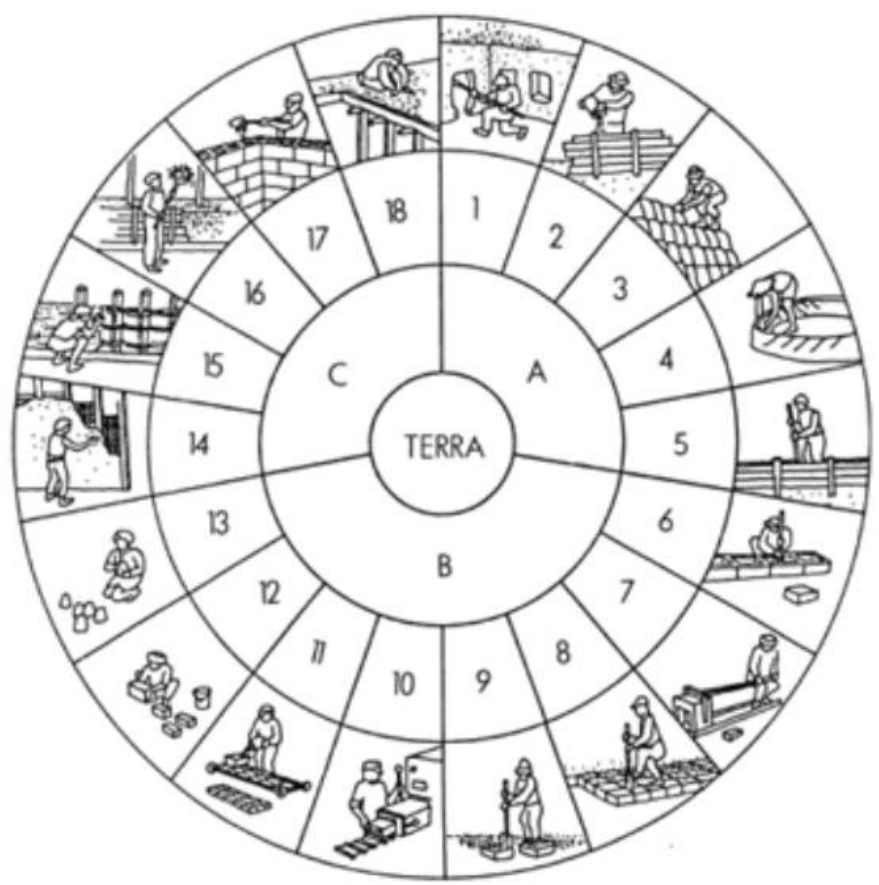

Fonte: Nito e Amorim (2012) adaptado de Guillard e Houben (1989)

O subgrupo A congrega os sistemas monolíticos (in situ) compreendem alternativas em que não existe separação entre material e componente construtivo - a transformação 
do solo e a edificação são constituídas num mesmo processo, podendo ser executadas de várias técnicas:

- (1) terra escavada, utilizada desde a pré-história, consiste em escavar o solo em zonas em que este apresente boas características mecânicas, na horizontal ou na vertical, formando grutas;

- (2) terra plástica, a terra moldada para construir blocos, que permite uma maior facilidade de moldagem e desmoldagem;

- (3) terra empilhada ou cob, que consiste em sobrepor por fiadas, montículos de terra misturada com palha. No fim, a estrutura é regularizada, aparando o material por corte vertical;

- (4) terra modelada, que se baseia em moldar barro à mão, construindo em altura por faixas; e,

- (5) terra compactada, onde o material é compactado entre fôrmas que se chamam taipais. A compactação pode ser feita manualmente, com um pilão de madeira ou, mais recentemente, com equipamentos pneumáticos.

O subgrupo $B$ é relativo aos sistemas em alvenaria tratam de vedações em terra, portantes ou não, utilizando blocos. Esses sistemas podem constituir diversas formas como arcos, cúpulas e abóbodas permitindo, assim, a flexibilidade de seus modos de construção. Na sua execução são utilizados diferentes tipos de unidades pré-fabricadas, que após a secagem, integram a construção. São exemplos:

- (6), (7), (8) e (9) blocos apiloados, prensados, cortados e em torrões, respectivamente, que podem ser simplesmente apiloados à mão, usando formas de madeira e um pilão ou recortados diretamente na terra. Modernamente, estes blocos são fabricados com o auxílio de máquinas e constituem os chamados BTC (blocos de terra comprimida), outra das técnicas com grande significado na nova construção de terra.

- (10) terra extrudada, que deriva do modo de produção dos tijolos cerâmicos. Consiste num método de fabricação por extrusão que permite obter não só blocos para alvenaria, mas também placas pré-fabricadas que podem ser aplicadas como revestimento de paredes.

- (11), (12) e (13) adobes mecânico, manual e moldados, respectivamente, que são blocos de terra bastante argilosa e areia, moldados sem compactação e secos ao sol, normalmente no próprio local da construção.

O subgrupo $C$ é representado pelos sistemas mistos, que consistem na associação de uma estrutura suporte no qual a utilização da terra é um elemento secundário, para encher ou revestir outras estruturas, que podem ser de madeira ou de outros materiais de origem vegetal, como cana e bambu. Fazem parte desse sistema:

- (14) a terra de recobrimento, utilizada para revestimento sobre estruturas de terra de vários dos tipos, como taipa e adobe.

- (15) a terra sobre engradado ou terra de guarnição, em que se inclui a taipa de mão e que consiste na aplicação de terra sobre uma estrutura de madeira ou bambu.

Gonçalves e Gomes (2012), além de tratar dos três grupos, acharam pertinente acrescentar um quarto, o sistema "D - Sistemas de Ligação", referindo-se aos sistemas de onde se utilizam da terra como argamassa de assentamento para blocos de alvenaria. 
As técnicas anteriormente apresentadas descrevem os tipos de construção com terra e a sua variedade de formas de execução. Seus exemplos retratam diversos modelos próprios de se trabalhar com terra, que podem ser combinados entre si, associando-se para melhor atender as circunstâncias exigidas do seu local de aplicação.

\section{Panorama mundial da utilização da terra na atualidade}

As técnicas de construção com terra, apesar de muito utilizadas no passado, entraram em um período de obsolescência em muitos países no início do século XIX cedendo à industrialização de materiais e processos construtivos tecnológicos, inclusive no Brasil (SANTOS, 2015; GALDINO, 2010). Santos (2015) enfatiza que, ainda nos dias atuais, poucos profissionais são capacitados para projetar e construir com terra, principalmente devido ao seu uso não ser ensinado em universidades.

$\mathrm{Na}$ construção civil, o surgimento de tecnologias fez com que muitos dos meios de produção artesanais presentes até então, fossem, aos poucos, sendo abandonados, substituídos por materiais e procedimentos que viriam a se universalizar. Entretanto, conforme afirmam Nito e Amorim (2012), no século XX, essa situação se modificou. Nito e Amorim (2012) e Galdino (2010) relacionam à luz da engenharia moderna, as construções contemporâneas com terra ao conceito da bioarquitetura, na qual o movimento moderno despertou em profissionais da área construtiva, possibilidades técnicas do uso desse material.

No contexto ambiental, Santos (2015) discorre sobre a utilização de terra como alternativa sustentável por apresentar materiais recicláveis e de baixa energia incorporada, contraposto aos materiais altamente industrializados como cimento, aço e blocos cerâmicos. Desta forma, no Brasil e no mundo, têm-se desenvolvido novos estudos e normas acerca de possibilidades construtivas na atualidade.

Exemplos disso são as associações em prol da construção com terra tem despertado o interesse de pesquisadores, como a já mencionada Rede Ibero-americana PROTERRA, de intercâmbio para o desenvolvimento e a transferência da tecnologia em arquitetura e construção com terra por meio da pesquisa, educação formal, oficinas e difusão; a Rede Terra Brasil, congregando profissionais, entidades de classe e a sociedade sobre esse tema, disseminando conhecimentos e transferência de tecnologia para o desenvolvimento científico no país; a Associação Brasileira de Materiais e Tecnologias Não-Convencionais (ABMTENC), que objetiva contribuir com a divulgação de construções com materiais naturais e não convencionais, inclusive a terra (SANTOS, 2015).

No panorama internacional, Pinheiro et al. (2016) salientam que, atualmente, Estados Unidos e Austrália são os países que possuem o maior número de escritórios e construtoras que trabalham com terra, destacando-se, também, países da Europa como Inglaterra, França, Alemanha, Espanha e Portugal. Olender (2006) destaca as associações na França, como o CRATerre e o Comitê Específico do ICOMOS para a Arquitetura em Terra; na Espanha, como o Centro de Investigação Navapalos e na América Latina, especialmente em países como Peru, Argentina, Colômbia e Chile. Já Santos (2015), além de mencionar o CRATerre, ainda discorre sobre o grupo Adobe in action nos Estados Unidos, o qual contribui para a organização do congresso americano de construção com terra, o EarthUSA e sobre os estudos na Inglaterra, na Universidade de Bath, a qual tem promovido capacitações sobre esse tipo de construção.

Outras associações são citadas por Franke (2017), como o Centro da Terra em Portugal, o Earth Building Association of Australia (EBAA) na Austrália e, no Chile, a Fundación Jofré. Na Alemanha, destaca-se o Dachverband Lehm (DVL), estabelecido em 1992 que, entre 
outros objetivos, focou-se no desenvolvimento de uma legislação para a construção em terra, publicando em 1998 as Lehmbau Regeln, atualizadas novamente em 2009.

Aliado as associações, normas e documentos de referências passaram a ser desenvolvidos pelo mundo, com o intuito de fornecer as disposições necessárias para que as técnicas de construção com terra obtivessem melhores desempenhos, proporcionassem segurança construtiva e ainda alcançassem a aceitação da população, trazendo prescrições, conselhos e orientações acerca de projetos, materiais, mão de obra e manutenção. Gonçalves e Gomes (2012) listam como as principais existentes no mundo: i) as normas da Neozelandesas Engineering Design of Earth Buildings, Earth Buildings not Requiring Specific Design e Materials and Workmanship for Earth Buildings que, além da terra compactada, adobe e bloco de terra comprimida, focam também na terra vazada; ii) o já mencionado código alemão Lehmbau Regeln, uma associação nãogovernamental para a construção com terra, que foi o primeiro código publicado na União Europeia; iii) a norma do Zimbabué, Rammed Earth Structures - Code of Practice, que foca na terra compactada; iv) a norma Australiana The Australian Earth Building Handbook; v) a norma do Novo México, Earthen Buildings Materials Code, sobre adobe, terra compactada, bloco de terra compactada e terra vazada; e, vi) o manual espanhol Bases para el Diseño y Construcción con Taipial do Ministério de Obras Públicas e Transportes, sobre terra compactada e adobe. Destaca-se que, quando essas normativas referem-se à taipa, trata-se de técnica equivalente a taipa de pilão, tal qual é conhecida no Brasil.

\section{Registro histórico e mapeamento da taipa de mão no Brasil}

No Brasil, a arquitetura de terra chegou com a colonização, primeiramente trazida pelos portugueses, tendo em vista que os nativos ainda não utilizavam esse material com este fim (LOPES et al., 2013; CARVALHO; LOPLES, 2012). Entretanto, considerando que no continente africano já se utilizava a terra, os escravos trazidos para o país detinham conhecimento de técnicas com seu uso para a construção, onde algumas tribos empregavam estruturas preenchidas com barro e, outras, o adobe (PISANI, 2004). Apesar de não ser possível mensurar o grau de contribuição desses povos, Olender (2006, p. 20) conta que:

"[...]os índios utilizavam em suas ocas engradados de madeira e folhas de palmeira para cobri-los e que os negros africanos tinham o costume de revestir as suas habitações com barro [...]".

Assim, as práticas indígenas e africanas se associaram às lusitanas para se adequar à realidade local e, com isso, se difundir para as demais regiões.

Dentre as técnicas utilizadas mais empregadas na arquitetura brasileira, tem-se o adobe, a taipa de pilão e a taipa de mão. $O$ adobe (Figura 4) é caracterizado como uma técnica de vedação vertical feita com blocos fabricados por colocação manual da massa, composta de terra e água, no interior de um molde apoiado em uma superfície plana, procedendo-se imediata desmoldagem. A forma de construir em adobe é semelhante à colocação do tijolo convencional, formando uma alvenaria. A taipa de pilão (Figura 5) trata-se de paredes construídas in loco com a compactação de camadas de terra úmida no interior de moldes (taipal ou tapial), geralmente de madeira, que vão se deslocando à medida que avança a construção. Recebe esta denominação por ser socada (apiloada) com o auxílio de uma mão de pilão (OLENDER, 2006; CARVALHO; LOPLES, 2012; PISANI, 2004).

Por fim, a taipa de mão (Figura 6) consiste na execução de paredes com tramas de madeira, constituída por paus verticais (pau-a-pique) presos, em ambos os lados, a paus 
CORDEIRO, Carol Cardoso Moura et al.

Construções vernáculas em terra: perspectiva histórica, técnica e contemporânea da taipa de mão

horizontais (ripas) sobre a qual é aplicada manualmente uma argamassa de barro que preenche seus vazios (OLENDER, 2006; CARVALHO; LOPLES, 2012; PISANI, 2004).

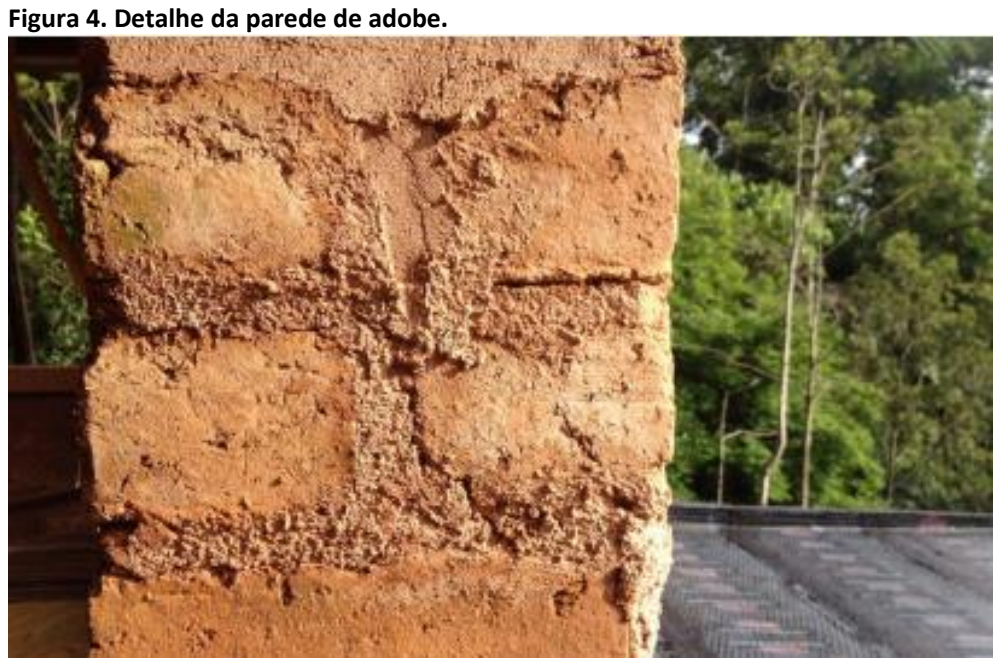

Fonte: Franke (2017).

Figura 4. Detalhe da parede de adobe.



Fonte: Taipal Construções em Terra².

Figura 6. Detalhe da parede de taipa de mão.

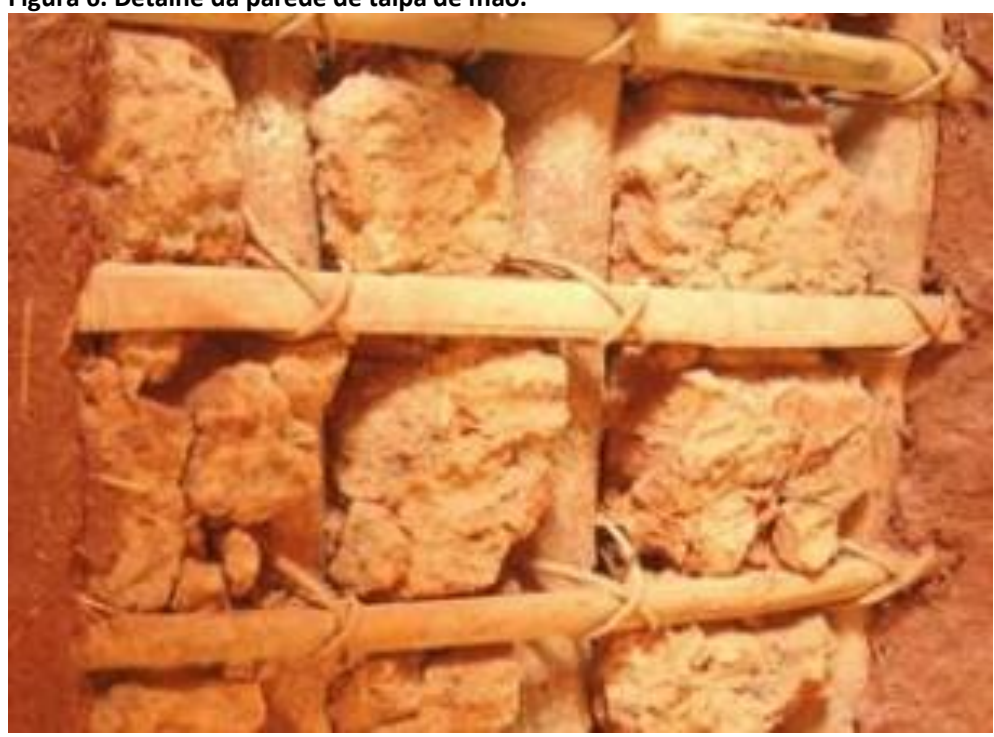

Fonte: Olender (2006). 
Passado o período de colonização, a terra ainda permaneceu enquanto método construtivo. No caminho traçado pelos bandeiristas nos estados de São Paulo, Minas Gerais, Mato Grosso e Goiás, as construções com terra formaram parte do patrimônio brasileiro (OLENDER, 2006; NITO; AMORIM, 2012).

Das técnicas elencadas, segundo Olender (2006), uma das mais encontradas na arquitetura brasileira é a taipa de mão, atribuída aos primeiros edifícios do Brasil. A depender da região, também é conhecida como taipa de sebe; pau a pique; barro armado; taipa de pescoção e tapona e sopapo (PISANI, 2004; OLENDER, 2006, SANTOS, 2015).

Construções como, o primeiro muro de Salvador, na Bahia, igrejas e casas de Ouro Preto e Diamantina, em Minas Gerais, as fortificações militares de Recife, em Pernambuco e as fazendas de café do Vale do Paraíba, em São Paulo, são exemplos de construções antigas em taipa de mão relacionados por Nito e Amorim (2012). No Estado do Rio de Janeiro, a técnica é bastante encontrada em construções antigas nas cidades do interior, como Valença, Vassouras, Barra do Piraí, Piraí, Paty do Alferes, entre outras (OLENDER, 2006).

Nas primeiras construções no interior do Piauí, Lopes et al. (2013) também relatam o uso da técnica em construções antigas e em construções mais recentes, como por exemplo, nas cidades de Uruçuí e de Assunção do Piauí. Além disso, recontam como frequente o uso de construções com taipa de mão em Teresina, oriundo do conhecimento empírico proveniente das zonas rurais do estado.

Pinheiro et al. (2016) remontam que, a partir da década de 1930, houve a retomada por arquitetos modernistas que tentavam unir a arquitetura popular com a erudita, citando obras em taipa de mão pelos arquitetos Lúcio Costa, em 1934, que projetou o Conjunto Modevale, no Estado de Minas Gerais. Acácio Gil Borsoi, em 1963, o conjunto habitacional Cajueiro Seco, em Pernambuco, e Lina Bo Bardi, em 1975, a Comunidade Curumim, no Estado de Sergipe.

Em São Sebastião, no estado de São Paulo, Galdino (2010) realizou um trabalho sobre as "casas de mão e barro" referindo-se ao emprego do pau-a-pique como técnica mais utilizada na região. O autor identificou casas remanescentes presentes em vilas e em núcleos urbanos localizados nas praias isoladas de Ilhabela, como o Saco do Sombrio, Guanxuma, Búzios, dentre outros. Reconheceu, ainda, o uso em bairros tradicionais de São Sebastião, como São Francisco da Praia, Figueira, Cigarras, Enseada e nos morros da Boa Vista e Abrigo.

Caser e Ino (2001) fizeram um levantamento de três projetos em taipa de mão no Brasil, edificados entre os anos de 1991 e 1992 no Espírito Santo, sendo eles a "Casa de Guarda" para Florestas Rio Doce (FRDSA), o protótipo de habitação "Moradia Ecológica", para Fundação Vale do Rio Doce (FVRD) e o "Centro de Vivências" do Parque Ecológico Morro da Manteigueira, enfatizando as soluções técnicas adotadas. As autoras concluíram que a taipa de mão, enquanto técnica construtiva vemácula, insere-se perfeitamente como alternativa construtiva moderna, diante do seu baixo custo, flexibilidade e racionalização do processo construtivo.

\section{Potencialidades da taipa de mão na contemporaneidade}

Lopes e Ino (2000) discorrem de um período em que a taipa de mão ficou abandonada e desconhecida enquanto possibilidade construtiva, inclusive nas universidades ligadas à construção civil. Carvalho e Lopes (2012), Santos (2015) e Franke (2017) atentam que, ao longo do tempo, essa técnica foi associada à pobreza, precariedade e construções provisórias, principalmente por ser relacionada à falta de recursos, a Doença de Chagas ${ }^{1}$ 
e devido à falta de conhecimento apropriado em sua execução, perdendo seu valor mesmo sendo uma técnica integrada à cultura do país. Franke (2017) explica que este estigma negativo é retrato de países onde a técnica foi empregada devido a necessidade de moradia e a falta de opção, como no Brasil, fundamentado em construções de má qualidade. As Figuras 7 e 8 retratam a taipa de mão executada sem revestimento final, resultando em frestas e deterioração.

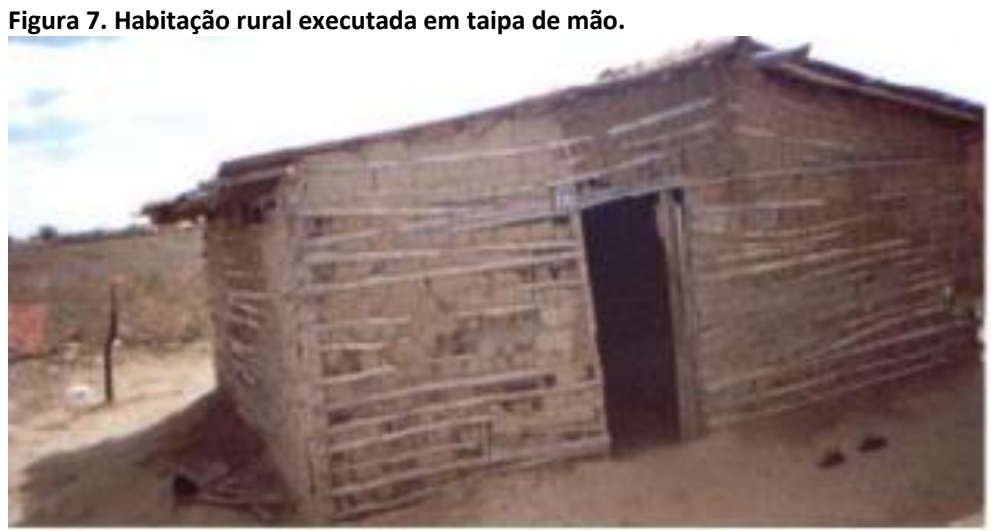

Fonte: Pisani (2003).

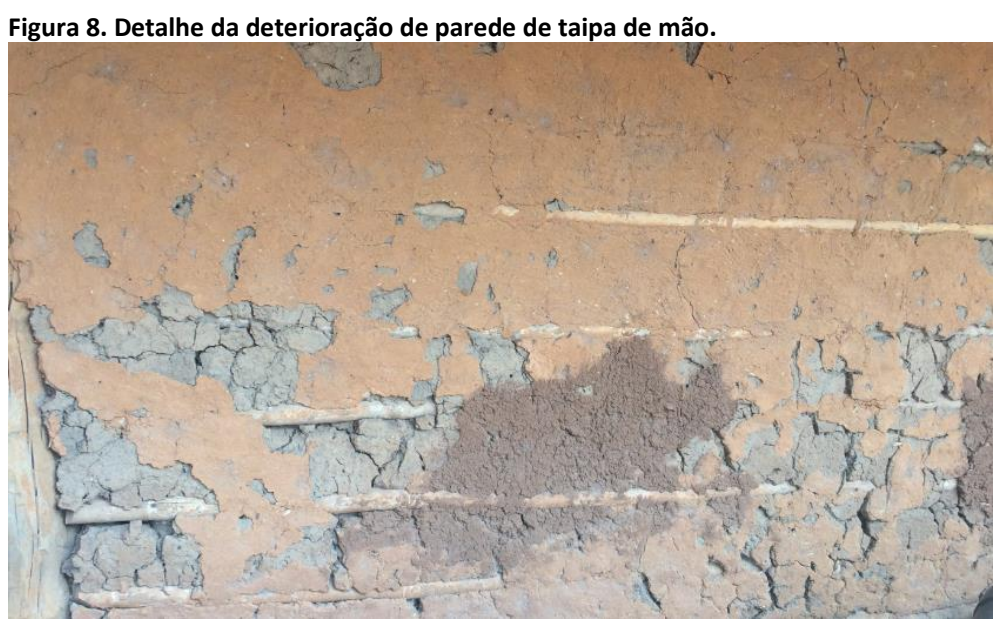

Fonte: Os autores.

Entretanto, Galdino (2010) expõe que apesar do período latente, as tramas de taipa de mão voltaram à tona, com o surgimento de novos paradigmas ligados à sustentabilidade e fortalecimento da cultura regional, retomando seu espaço paulatinamente.

Franke (2017) registra inovações da taipa de mão na contemporaneidade, sendo elas: i) afastamento da base da edificação do solo e impermeabilização junto a estrutura de madeira, o que diminui a deterioração por efeito da umidade; ii) mecanização da mistura de terra com água e fibras, possibilitando otimização dos recursos; iii) estrutura de suporte metálica, em substituição das tramas de madeira, oferecendo maior resistência estrutural e rapidez de execução; e iv) estrutura de suporte pré-fabricada em formato de painéis, que podem ser montados independentemente. 
Figura 9. Inovações na Taipa de mão: (a esquerda) estrutura metálica em substituição das tramas de madeira; (a direita) estrutura em painel de madeira pré-fabricado.

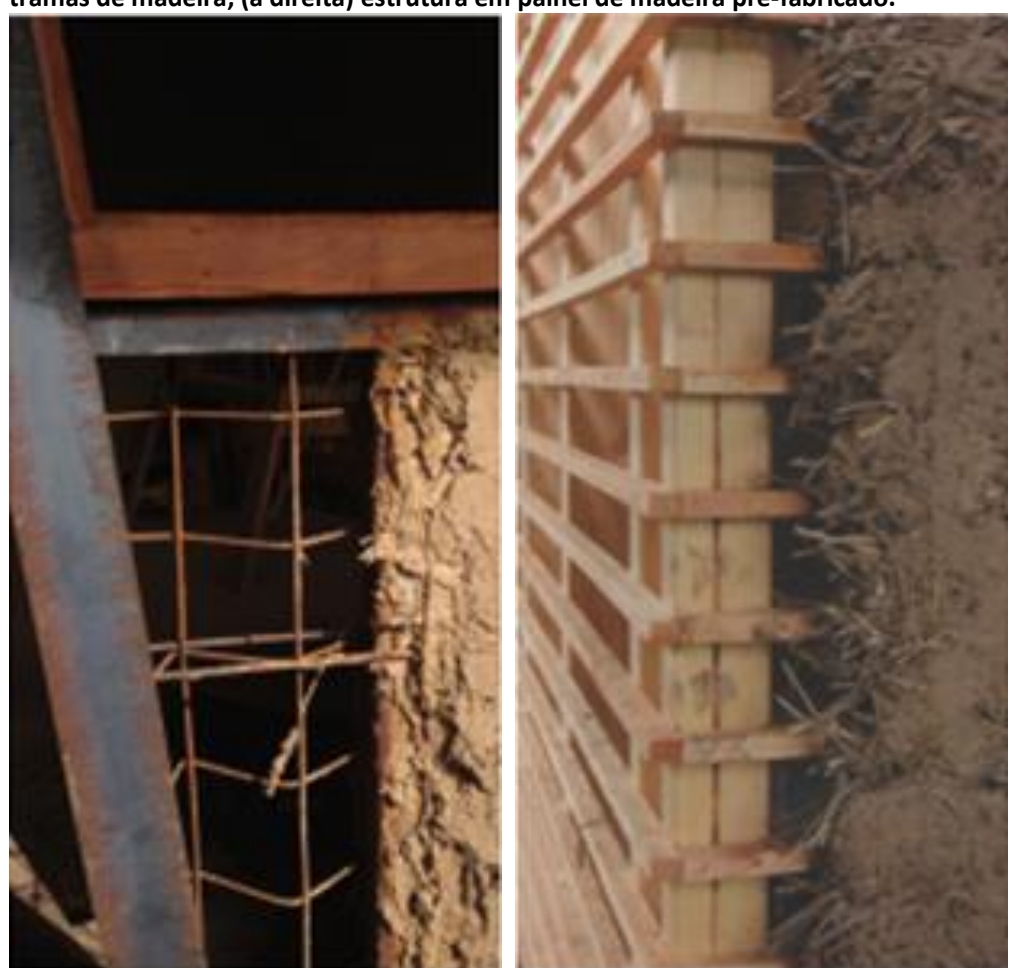

Fonte: Franke (2017) e Franke (2017) apud Volhard, F. (2016).

Segundo Santos (2015), o maior desafio trata-se do desconhecimento das vantagens dessas construções. Carvalho e Lopes (2012), Gomes e Gonçalves (2012) e Pisani (2004) relacionam as potencialidades da terra, citando como benefícios:

a) A baixa condutibilidade térmica das paredes de barro;

b) O conforto hídrico, relativo à regulação da umidade ambiental;

c) A absorção dos ruídos, por se tratar de um material poroso;

d) A possibilidade de ocorrer passagem do ar entre os fechamentos com consequente renovação do ar;

e) Economia de energia na sua construção;

f) Processo totalmente reciclável, podendo ser demolida e reaproveitada múltiplas vezes;

g) Podem apresentar baixo custo e contribuir significativamente no processo de produção social do habitat;

h) Oportunidade de autoconstrução;

i) Possibilidade de variações arquitetônicas no desenvolvimento dos projetos.

Neves e Farias (2011) apresentam as vantagens relativas à técnica de sistema misto, onde se enquadra a técnica taipa de mão, conforme classificação da Figura 3 apresentado anteriormente. As vantagens são:

a) É um sistema ecológico e sustentável que responde com qualidade as condições ambientais diversas;

b) São naturalmente adaptáveis à disponibilidade de materiais locais; 
c) Em zonas de elevada sismicidade, as técnicas mistas apresentam desempenho estrutural e de flexibilidade compatível com os esforços gerados, podendo ser caracterizadas como técnicas sismorresistentes.

d) As técnicas mistas propiciam a participação comunitária e o trabalho da mão-deobra local.

Já Lopes et al. (2013) tratam das vantagens falando especificamente da taipa de mão, enfatizando características como a facilidade de execução, inclusive por mão de obra não qualificada, excelente desempenho térmico e baixo consumo de energia. Lopes e Ino (2000, p.2) também tratam das vantagens da taipa de mão, afirmando que:

\begin{abstract}
[...] é uma técnica facilmente assimilável e transmissível, e de simples execução, podendo ser adotada facilmente, por mão de obra não qualificada. Apresenta excelente desempenho térmico, é ecologicamente equilibrada, utiliza materiais locais e renováveis, que não agridem à natureza e são encontrados facilmente, além de apresentar baixo consumo de energia, tanto no processamento dos materiais quanto na construção em si.
\end{abstract}

Caser e Ino (2001) relacionam a construção em taipa de mão como uma maneira direta e efetiva de contribuir para o meio ambiente, ajudando a alcançar o desenvolvimento sustentável no planeta. Além disso, também pontuam a possibilidade das pessoas poderem utilizar uma técnica artesanal para expressar uma vida mais integrativa e ecológica. Franke (2017) observa que a simplicidade dessa técnica torna a construção intuitiva, o que, segundo essa autora é uma das suas maiores vantagens.

Neste contexto, Galdino (2010) identifica que o uso da taipa de mão é uma opção muito positiva. Lopes et al. (2013) acreditam que essa técnica pode ser mais uma alternativa na solução dos problemas habitacionais, devido as suas vantagens, desde que seguidos os procedimentos técnicos corretos.

\title{
Conclusão
}

A exploração e disseminação do conhecimento da arquitetura e construção com terra tornam-se fundamentais para o resgate de técnicas vernáculas na atualidade. Os materiais sustentáveis de menor impacto ambiental precisam, sempre que possível, substituir os materiais de construção convencionais, de modo a minimizar os impactos negativos que os mesmos geram para o meio ambiente. Portanto, é necessário reconhecer e restabelecer o uso de materiais locais e técnicas tradicionais mais adequadas que podem ter menor impacto no ambiente.

Apesar do uso da terra como material de construção ter passado por um período de obsolescência, sendo fortemente substituída pela industrialização de materiais e tecnologias construtivas, percebe-se que, com o fomento pela sustentabilidade, tem-se buscado o retorno dessas práticas construtivas em diversos países.

O legado da construção em taipa de mão no Brasil dentro da perspectiva histórica demonstra a importância da sua valorização e preservação, já que a mesma foi inserida desde o período da colonização e perdura, hodiernamente, em diversas regiões do país.

Ainda em vista da questão da sustentabilidade, a taipa de mão apresentou diversas vantagens quanto a sua utilização, principalmente quanto às suas características ecológicas, de conforto térmico, hídrico e sonoro, o baixo consumo de energia e a possibilidade de retrofit. 
Entende-se que para o seu uso na atualidade, faz-se necessário o desenvolvimento de um procedimento técnico com normas específicas para aperfeiçoar a execução da estrutura, dos sistemas de amarração, ancoragens e montagens, ampliando assim a sua durabilidade.

Coloca-se ainda a importância da influência não só acadêmica, mas política e governamental na disseminação e conscientização da população quanto à eficiência das edificações construídas em taipa de mão como solução sustentável, para que o retorno da técnica não seja margeada pelo preconceito e possa ser não só aceita, mas escolhida pelos seus usuários

\section{Agradecimentos}

Os autores agradecem a Fundação de Amparo e Pesquisa do Mato Grosso pela bolsa de mestrado concedida a autora Carol Cardoso Moura Cordeiro.

\section{Notas}

(1) As edificações em taipa de mão são constantemente associadas como criadouros do inseto vetor conhecido como barbeiro, transmissor da doença de Chagas (PINHEIRO et al., 2016).

(2) Taipal Construções em Terra, Escultura Elisa Bracher. Disponível em: http://taipal.com.br/portfolio/esculturaelisa-bracher/\#. Acesso em: 27 de julho de 2018.

\section{Referências}

CANTEIRO, F.; PISANI, M. Taipa de mão: História e Contemporaneidade. In: SEMINÁRIO ARQUITETURA E CONSTRUÇÃO COM TERRA NO BRASIL, 1., SEMINÁRIO ARQUITECTURA DE TERRA EM PORTUGAL, 4., 2006, Ouro Preto. Anais [...]. Ouro Preto: UFMG, UFOP, PUC-MG, 2006.

CARBAJAL, F.; RUIZ, G.; SCHEXNAYDER, C. J. Quincha construction in Perú. Practice Periodical on Structural Design and Construction, v. 10, n. 1, p. 56-62, 2005. DOl:https://doi.org/10.1061/(ASCE)1084-0680(2005)10:1(56)

CARVALHO, R. N. F. M. de; MIRANDA, Cybelle Salvador. A taipa como patrimônio cultural: a preservação do saber fazer. RCT-Revista de Ciência e Tecnologia, v. 1, n. 1, 2015.

CARVALHO, T. M. P. de; LOPES, W. G. R. A arquitetura de terra e o desenvolvimento sustentável na construção civil. In: CONGRESSO NORTE NORDESTE DE PESQUISA E INOVAÇÃO, 7., 2012, Palmas. Anais [...]. Palmas: CONEPI, 2012. p. $1-7$.

CASER, K.; INO, A. 23 projetos em taipa de mão: análise de soluções incorporadas à técnica tradicional. In: ENCONTRO NACIONAL SOBRE EDIFICAÇÕES E COMUNIDADES SUSTENTÁVEIS, 2., ENCONTRO LATINO-AMERICANO SOBRE EDIFICAÇÕES E COMUNIDADES SUSTENTÁVEIS, 1., 2001, Canela. Anais [...]. Canela: ANTAC, 2001. p. 155-162.

DRESCH, A.; LACERDA, D. P; ANTUNES JÚNIOR, J. A. V. Design Science Research: Método de Pesquisa para Avanço da Ciência e Tecnologia. Porto Alegre: Bookman, 2014. 204p.

FERNANDES, J. E. P.; MATEUS, R.; BRAGANÇA, L. Princípios de sustentabilidade na arquitectura vernacular em Portugal. In: CONGRESSO NACIONAL DA CONSTRUÇÃO, 4., 2012, Coimbra. Anais [...]. Universidade de Coimbra: Coimbra, 2012. p. 1-12.

FIGUEIRA, A. F. T. O carácter vernáculo na construção com terra no panorama contemporâneo. 2016. 280 f. Tese (Doutorado) - Curso de Arquitetura, Universidade de Lisboa, Lisboa, 2015.

FRANKE, L. N. Arquitetura Contemporânea em Terra: modos de ver e fazer. 2017. 237 f. Dissertação (Mestrado) Curso de Arquitetura, Faculdade de Arquitetura da Universidade do Porto, Portugal, 2017. 
GALDINO, C.. Casas de mãos e barro: a arquitetura caiçara de São Sebastião. Revista Cadernos do Ceom, v. 23, n. 32, p. 77-98, 2010.

GONÇALVES, T. D.; GOMES, M. I. Construção de terra crua: potencialidades e questões em aberto. Jornadas LNEC, Lisboa, v. 18, 2012.

JOFFROY, T.; GUILLAUD, H.; LE TIEC, J-M. Architectures contemporaines en terre crue: sur les traces de Hassan Fathy. In: UNESCO INTERNATIONAL COLLOQUIUM ON THE CONSERVATION OF WORLD HERITAGE EARTHEN ARCHITECTURE. 2012. Proceedings [... ]. Paris: CRATerre, 2013. p. 218-225.

LOPES, W. G. R. et al. A Taipa de Mão em Teresina, Piauí, Brasil: a Improvisação e o Uso de Procedimentos Construtivos. digitAR-Revista Digital de Arqueologia, Arquitectura e Artes, n. 1, Coimbra, 2013.

LOPES, W. G. R.; INO, A. Habitação em taipa de mão: alternativa de construção mais sustentável. In: ENCONTRO NACIONAL DE TECNOLOGIA DO AMBIENTE CONSTRUÍDO, 8., 2000, Salvador. Anais [...]. Salvador: ANTAC, 2000. p. 173-180.

MORANDI, M. I. W. M.; CAMARGO, L. F. R. Revisão sistemática da literatura. In: DRESCH, A.; LACERDA, D. P.; ANTUNES JÚNIOR, J. A. V. Design Science Research: Método de Pesquisa para Avanço da Ciência e Tecnologia. Porto Alegre: Bookman, 2015. Cap. 6. p. 141-171.

NEVES, C. Resgate e Atualização do Construir com Terra: O Projeto PROTERRA. In: CONFERÊNCIA LATINOAMERICANA DE CONSTRUÇÃO SUSTENTÁVEL, ENCONTRO NACIONAL DE TECNOLOGIA DO AMBIENTE CONSTRUÍDO, 10., 2004, São Paulo. Anais [...]. São Paulo: ANTAC, 2004.

NEVES, C.; FARIA, O. B. Técnicas de construção com terra. Bauru, SP: FEB-UNESP/PROTERRA: 197 p. 2011.

NITO, M. K. S.; AMORIM, A. M. M. C. Sistemas construtivos em terra crua: panorama da América Latina nos últimos 30 anos e suas referências técnicas históricas. In: CASTRO, Ana; ASSAL, Marianna Boghosian Al. Revista Cadernos de Pesquisa da Escola da Cidade. São Paulo: Editora da Cidade, 2015. p. 11-18.

OLENDER, M. C. H. L. A técnica do Pau-a-pique: subsídios para a sua preservação. 2006, 94 f. Dissertação (Mestrado) - Curso de Arquitetura e Urbanismo, Faculdade de Arquitetura, Universidade Federal da Bahia, Salvador, 2006.

PACHECO-TORGAL, F.; JALALI, Said. Earth construction: Lessons from the past for future eco-efficient construction. Construction and building materials, v. 29, p. 512-519, 2011. DOI:https://doi.org/10.1016/j.conbuildmat.2011.10.054

PINHEIRO, L.; RANGEL, B.; GUIMARÃES, A., SILVA, A. Panorama da produção de obras em terra crua com design contemporâneo nos últimos 60 anos no Brasil. In: CONGRESSO INTERNACIONAL DE HISTÓRIA DA CONSTRUÇÃO LUSO-BRASILEIRA, 2, 2016, Porto. Anais [...]. Porto: CEAU-FAUP, 2016.

PINTO, J. et al. Corn's cob as a potential ecological thermal insulation material. Energy and Buildings, v. 43, n. 8, p. 1985-1990, 2011. DOI:https://doi.org/10.1016/j.enbuild.2011.04.004

PISANI, Maria Augusta Justi. Taipas. In: COLLET, Gilda B. et al. Relatório de Pesquisa: Promoção do Desenvolvimento Sustentável: Comunidades do Semi-Árido, MACKPESQUISA: São Paulo, 2003.

PISANI, M. A. J. Taipas: a arquitetura de terra. Sinergia-Revista do Centro Federal de Educação Tecnológica de São Paulo, São Paulo, v. 5, n. 1, 2004.

SAMEH, Sherin H. Promoting earth architecture as a sustainable construction technique in Egypt. Journal of cleaner production, v. 65, p. 362-373, 2014. DOI:https://doi.org/10.1016/j.jclepro.2013.08.046

SANTOS, C. A. Construção com terra no Brasil: panorama, normatização e prototipagem com terra ensacada. 2015. Dissertação (Mestrado em Arquitetura e Urbanismo) - Centro Tecnológico, Universidade Federal de Santa Catarina, Florianópolis, 2015. 
CORDEIRO, Carol Cardoso Moura et al.

Construções vernáculas em terra: perspectiva histórica, técnica e contemporânea da taipa de mão

SOUZA, G. A. A. et al. Arquitetura de terra: alternativa sustentável para os impactos ambientais causados pela construção civil. E-xacta, v. 8, n. 1, p. 1-13, Belo Horizonte, 2015.

UNESCO, Lista de Patrimônio Cultural. Disponível em: http://whc.unesco.org/en/list/. Acesso em: 15 de março de 2018.

\section{${ }^{1}$ Carol Cardoso Moura Cordeiro}

Engenheira Civil. Mestranda em Engenharia de Edificações e Ambiental. Endereço postal: Avenida Fernando Correa da Costa, 2367, Faculdade de Arquitetura, Engenharia e Tecnologia, Cuiabá, MT, Brasil, CEP 78060-900

\section{Douglas Queiroz Brandão}

Engenheiro Civil. Doutor em Engenharia de Produção. Professor do Departamento de Engenharia Civil e do Programa de Pós-graduação em Engenharia de Edificações e Ambiental da Universidade Federal de Mato Grosso Endereço postal: Avenida Fernando Correa da Costa, 2367, Faculdade de Arquitetura, Engenharia e Tecnologia, Cuiabá, MT, Brasil, CEP 78060-900

\section{Luciane Cleonice Durante}

Engenheira Civil. Doutora em Física Ambiental. professora do Departamento de Arquitetura e Urbanismo e do Programa de Pós-graduação em Engenharia de Edificações e Ambiental da Universidade Federal de Mato Grosso. Endereço postal: Avenida Fernando Correa da Costa, 2367, Faculdade de Arquitetura, Engenharia e Tecnologia, Cuiabá, MT, Brasil, CEP 78060-900

\section{Ivan Julio Apolonio Callejas}

Engenheiro Civil. Doutor em Física Ambiental. Professor do Departamento de Arquitetura e Urbanismo e do Programa de Pós-graduação em Engenharia de Edificações e Ambiental da Universidade Federal de Mato Grosso. Endereço postal: Avenida Fernando Correa da Costa, 2367, Faculdade de Arquitetura, Engenharia e Tecnologia, Cuiabá, MT, Brasil, CEP 78060-900 